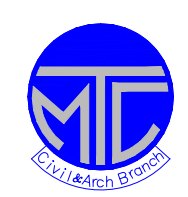

ICCAE

Military Technical College

Kobry Elkobbah,

Cairo, Egypt 7th International Conference

On Civil \& Architecture

Engineering

\title{
SEEPAGE UNDERNEATH THE FLOOR OF PUMPING STATION THROUGH IMPERFECT BED LINING
}

\author{
Mohamed N. SALEM* \\ Water and Water Structure Engineering Dept.
}

Contact Information: Dr. Mohamed Nageeb Salem,

e-mail: mnsa30@yahoo.com, Phone: 010-7333029, 055-2570104

\section{ABSTRACT}

The problem of seepage under the floor of a pumping station is investigated here. The upstream and the downstream cracks assumed to occur between lining and the ends of the floor, i.e., $L_{1}=0$ and $L_{2}=0$. The floor is provided with two sheet piles of different depths at the two ends and it has a vertical rise. The pumping station is resting on a permeable layer of finite depth. Effects of the different sheet pile depths and location of the vertical rise on the piezometric head underneath the floor, exit gradients and seepage discharge have been analyzed using Finite Element Program and graphically represented in dimensionless charts.

\section{KEY WORDS}

Pumping Station, Finite Element, Seepage, Uplift Pressure and FORTRAN.

* Associate professor, Dept. of Water and Water Structure Engineering, Zagazig University, Zagazig, Egypt. 


\section{NOMENCLATURE}

D : Height of the vertical rise;

$\mathrm{F}_{1} \quad$ : Length of the upstream part of the floor;

$\mathrm{F}_{2}$ : Length of the downstream part of the floor;

$\mathrm{F} \quad$ : Horizontal length of the floor;

$\mathrm{H}_{1} \quad$ : Upstream water depth;

$\mathrm{H}_{2}$ : Downstream water depth;

$\mathrm{H}_{\mathrm{s}} \quad$ : Total static head;

I : Exit hydraulic gradient through the upstream crack;

$\mathrm{k}_{\mathrm{x}, \mathrm{y}} \quad$ : Permeability in $\mathrm{x}$ - and $\mathrm{y}$-directions respectively;

$L_{0} \quad$ : Upstream reach before the upstream crack;

$\mathrm{L}_{1} \quad$ : Upstream edge just before the upstream edge of the floor, taken $=0$ in this work;

$\mathrm{L}_{2} \quad$ : Downstream lining just before the downstream crack, taken $=0$ in this work;

$\mathrm{L}_{3} \quad$ : Downstream reach after the downstream crack;

q : Seepage discharge per unit width;

$W_{1} \quad$ : Width of the upstream crack, taken constant in this study;

$W_{2}$ : Width of the downstream crack, taken constant in this study;

$\mathrm{T} \quad$ : Depth of the soil strata;

$x \quad$ : Length measured from the upstream edge of the floor;

$\phi \quad$ : Velocity potential, piezometric head and

\section{INTRODUCTION}

The cornerstone of the Tushka Project (South Valley Project in Egypt) is a plan to ultimately irrigate more than 500,000 acres of undeveloped desert land. The government has nearly completed the region's water delivery systems, which include the world's largest water pumping station and the Sheikh Zayed Canal. The pumping station will convey more than 20,000 acre-feet a day. The cracks between the upstream and the downstream floor ends and canal lining may be developed due to many factors such as imperfect lining or gradual deterioration of lining. In such case, the uplift pressures and exit gradients may endanger the stability of this huge structure. In this paper, the effect of crack existence in bed lining on uplift pressures, exit gradients and seepage discharge is studied numerically using finite element method. FORTRAN program is prepared to solve this seepage problem. 
The problem of two-dimensional confined seepage beneath hydraulic structure have been extensively investigated analytically, numerically, and experimentally, for different boundary conditions and floor configurations, [1, 2, 4, 5 and 6]. The investigation is extended for the cases of unlined canals [1, 3, 5, 7 and 9]. It was also investigated for lined canals with upstream and downstream bed cracks using the only same depths of sheet piles, different depths were not investigated, [2]. The boundary element method was used in the previous work taking into consideration the crack width, crack location which has minor effects on the pressure distribution. In the present work, more investigations are carried out using finite element program to investigate wider range of sheet pile depths using two rows of sheet piles of same and different depths. Dimensionless charts are presented as design curves in which we can enter the relative depths of the two sheet piles to estimate the uplift pressure distribution, exit gradients and seepage discharge. A FORTRAN program is prepared to solve the problem using finite element method.

\section{THEORETICAL STUDY}

The investigated domain represents an ideal (incompressible) flow through porous media is presented in Fig. 1. Laplace's equation for two-dimensional flow is used to model this domain considering the piezometric potential head as $\phi$.

Laplace's equation for two-dimensional flow is given by:

$$
\mathrm{k}_{\mathrm{x}} \frac{\partial^{2} \phi}{\partial \mathrm{x}^{2}}+\mathrm{k}_{\mathrm{y}} \frac{\partial^{2} \phi}{\partial \mathrm{y}^{2}}=0
$$

Where $\phi$ is the piezometric head, $k_{x}$ and $k_{y}$ are the soil permeability in $x$ - and $y$ directions respectively.

\section{The boundary conditions of this domain are either: -}

\section{i- Constant boundary}

The constant boundary condition is represented by $\phi=\mathrm{H}_{1}$, which is considered applicable at the upstream crack and $\phi=\mathrm{H}_{2}$ is applicable at the downstream crack. or

\section{ii-No flow conditions}

The no flow condition is considered applicable at the floor surface, upstream and downstream lining, upstream and downstream sides of the sheet piles, and the vertical imaginary boundaries at the end of the upstream and the downstream reaches and are represented by $\frac{\partial \phi}{\partial \mathrm{n}}=0$, as shown in Fig. 1 


\subsection{Finite Element Formulation}

The finite element method has been successfully applied in solving Laplace's Equation for two-dimensional flow [7, 8, and 9]. The method is superior over other numerical solution techniques due to its great ability to model local concentration of potentials at the desired portions of the investigated domain. Four-node isoparametric quadrilateral element with one degree of freedom for each node representing the fluid potential $\phi$ is chosen for this study, as shown in Fig. 2.

\subsection{Computer Program}

The in-hand problem is a two-dimensional flow of an ideal fluid through porous media. A finite element program is prepared using Fortran 90 programming language to solve Laplace's equation with the boundary conditions as shown in Fig. 2. The domain is composed of four-node quadrilateral elements. The global conductivity relation is represented by:

$$
[\mathrm{K}]\{\phi\}=\{\mathrm{q}\}
$$

Where $[\mathrm{K}]$ is the conductivity matrix

The program output results include flow rate, uplift pressures and exit gradients. Some effort is conducted in the geometry subroutine to simulate the changes in domain dimensions and the boundary conditions due to the existence of sheet pile of very small thickness.

\section{PARAMETRIC STUDY}

To achieve the research objective, a parametric study is conducted to assess and quantify the effect of each chosen parameter on the relative uplift pressure, relative exit gradient, and relative seepage discharge. These parameters are further explained as:

(i) Effect of relative depth of the upstream sheet pile, (ii) Effect of the relative depth of the downstream sheet pile, (iii) Effect of the relative depth of the two sheet piles,

(iv) Effect of the location of the vertical rise, (v) Effect of the relative depth of the pervious layer on each of the following :

- The relative uplift pressure.

- The relative exit gradient through the upstream crack.

- The relative seepage discharge.

\section{ANALYSIS OF THE RESULTS}


The output results of the computer program are analyzed and graphically represented using dimensionless graphs to investigate the effect of each individual parameter on seepage characteristics.

\subsection{Effect of the Relative Depth of Upstream Sheet Pile 4.1.1 Effect of the Relative Depth of Upstream Sheet Pile on the Relative Uplift Pressure:}

Fig. 3 shows the effect of relative depth of the upstream sheet pile, $d_{1} / F$, on the relative uplift pressure under the floor of the pumping station. The relative uplift pressures are considerably increased due to increasing the upstream sheet pile depth. The maximum increase in the uplift pressure, about $60 \%$, is obtained at the upstream end of the floor (just downstream the upstream sheet pile). This increase may be attributed to gradual holding of building up of pressures resulting from upstream sheet pile depth increasing. The increasing rate of the uplift pressures gradually decreases towards the downstream, due to the increased distance from the obstruction of flow lines. The increase in the relative uplift pressure is about $20 \%$ at the downstream end of the upstream part of the floor. However, About $7 \%$ increase is obtained at the downstream part of the floor. This reduction in the relative uplift pressure may be attributed to the drop in the structure floor.

For the case of no downstream sheet pile, the same increasing rate in the relative uplift pressures under the upstream part of the floor is observed due to the long distance from the downstream sheet pile. Also, no effect is noticed at the downstream end of the floor, as shown in Fig. 6.

\subsubsection{Effect of the Relative Depth of Upstream Sheet Pile on the Relative Exit Gradient Through the Upstream Crack}

About $13 \%$ decrease in the relative exit gradient just upstream the upstream part of the floor is obtained due to increasing the relative depth of the upstream sheet pile from 0.05 to 0.35 due to the greater path of flow, as shown in Fig. 4. The same decreasing rate is obtained for the case of no downstream sheet pile due to the long distance between the downstream sheet pile and exit crack, Fig. 7 .

\subsubsection{Effect of the Relative Depth of Upstream Sheet Pile on the Relative Seepage Discharge}

Fig. 5 shows that about $11 \%$ decrease in the relative seepage discharge could be obtained due to increasing the relative depth of the upstream sheet pile from 0.05 to 0.35 resulted from longer path of flow. Nearly same decrease is obtained in the relative seepage discharge is obtained for the case of no downstream sheet pile as presented in Fig. 8.

\subsection{Effect of the Relative Depth of the Downstream Sheet Pile}




\subsubsection{Effect of the Relative Depth of the Downstream Sheet Pile on the Relative Uplift Pressure under the Floor}

The effect of the relative depth of the downstream sheet pile on the relative uplift pressure under the floor is shown in Fig. 9. The figure shows that about $9 \%$ decrease in the relative uplift pressure is obtained at the upstream end of the upstream part of the floor due to the increase of the relative depth of the downstream sheet pile from 0.05 to 0.35 , as increasing the beginning flow path of the downstream sheet pile. The decreasing rate increases towards downstream, it reaches $11 \%$ under the downstream end of the upstream part of the floor and $23 \%$ at the downstream end of the floor, (more near to the abrupt change resulted from downstream sheet pile existence). Also, Fig. 12 shows the case in which no upstream sheet pile is installed. The figure shows that nearly the same decreasing rate is obtained at the two ends of the upstream part of the floor, (far from the changes in head resulting from downstream sheet pile location), but the decreasing rate at downstream end of the downstream part reaches $26 \%$, (most adjacent to the downstream sheet pile).

\subsubsection{Effect of the Relative Depth of the Downstream Sheet Pile on the Relative Exit Gradient}

About $8 \%$ decrease in the relative exit gradient is obtained as a result of seepage longer path in the beginning, as shown in Fig. 10. Fig. 13 represent the same relation for no upstream sheet pile and about $10 \%$ reduction is obtained in the relative exit gradient.

\subsubsection{Effect of the Relative Depth of the Downstream Sheet Pile on the Relative Seepage Discharge}

Fig. 11 shows that about $8 \%$ decrease in the relative seepage discharge is obtained due to increasing the relative depth of the downstream sheet pile depth from 0.05 to 0.35 . However, about $10 \%$ decrease in the relative seepage discharge is obtained for the case of no upstream sheet pile installed, Fig. 14.

\subsection{Effect of the Relative Depth of the Two Sheet Piles \\ 4.3.1 Effect of the Relative Depth of the Two Sheet Piles on the Relative Uplift Pressure}

As the relative depth of the two sheet piles increases, the relative uplift pressures increase to be more than double its original value at the upstream end of the upstream part of the floor, as shown in Fig. 15 due to the increase in of the upstream sheet pile depth. In contrast, the relative uplift pressures decrease through the vertical rise and downstream part of the floor, due to longer path of flow at the beginning. Moreover, no effect is obtained at the upstream part of the vertical rise and the decreasing rate increases gradually thereafter. About $28 \%$ decrease in relative uplift pressure original value occurs at the downstream end of the floor, Fig. 15. 


\subsubsection{Effect of the Relative Depth of the Two Sheet Piles on the Relative Exit Gradient}

About $36 \%$ decrease in the relative exit gradient is obtained due to increasing the relative depth of the two sheet piles from 0 to 0.35 ; this may be attributed to longer path of flow, Fig.16.

\subsubsection{Effect of the Relative Depth of the Two Sheet Piles on the Relative Seepage Discharge}

Fig.17 shows that about $23 \%$ decrease in the relative seepage discharge is obtained due to increasing the two sheet piles depths from 0 to 0.35 , more head drops are achieved for the existence of two sheet piles that decrease the flow discharge.

\subsection{Effect of the Location of the Vertical Rise}

The relative vertical rise location, $F_{1} / F$, is used to determine the location of the vertical rise of the pumping station floor.

\subsubsection{Effect of the Location of the Vertical Rise on the Relative Uplift Pressure}

As the relative length of the upstream part of the floor, $F_{1} / F$, increases from 0.2 to 0.8 , about $9 \%$ increase in the relative uplift pressures is obtained at the upstream half of the downstream part of the floor, due to the location of the vertical rise become more near to the beginning of flow. The opposite occurs under the upstream half of the upstream part of the floor, about $5 \%$ decrease in the relative uplift pressures occurs under the upstream end of the upstream part of the floor, as shown in Fig. 18.

\subsubsection{Effect of the Location of the Vertical Rise on the Relative Exit Gradient}

Fig.19 shows that a relatively small decrease in the relative exit gradient, about $4 \%$, is obtained due to increasing the relative location of the vertical rise, $F_{1} / F$. This may be attributed to that the same length of flow is found in all cases.

\subsubsection{Effect of the Location of the Vertical Rise on the Relative Seepage Discharge}

About $4 \%$ decrease in the relative seepage discharge is obtained due to increasing the relative location of the vertical rise, $F_{1} / F$, as shown in Fig. 20. And this may be attributed to the same reason as before. 


\subsection{Effect of the Relative Depth of the Pervious Layer \\ 4.5.1 Effect of the Relative Depth of the Pervious Layer on the Relative Uplift Pressure}

Very slight decrease in the relative uplift pressures is noticed under the upstream part of the floor. The decreasing rate in the uplift pressure increases gradually through the vertical rise and under the downstream part of the floor, reaching about $4 \%$ at the end of the floor as shown in Fig. 21.

\subsubsection{Effect of the Relative Depth of the Pervious Layer on the Relative Exit Gradient}

Fig. 22 shows that increasing the relative depth of the upstream pervious layer resulted in about $13 \%$ increase in the relative exit gradient.

\subsubsection{Effect of the Relative Depth of the Pervious Layer on the Relative Seepage Discharge:}

Fig. 23 shows that about $13 \%$ increase in the relative seepage discharge resulted from increasing the relative depth of the pervious layer.

\section{CONCLUSIONS}

1- About $26 \%$ decrease in relative uplift pressure is obtained at the downstream end of the floor for no sheet pile at the downstream end of the floor. But only $23 \%$ decrease at the downstream end of the floor in the case of the upstream sheet pile.

2- The relative uplift pressure increases to be doubled in its value at the upstream end of the floor but it decreases to be about $28 \%$ of its original value at the downstream end of the floor.

3- About $36 \%$ decrease in the relative exit gradient is obtained for the increasing of the two sheet piles from 0 to 0.35 .

4- The increase in the relative sheet pile depths from 0 to 0.35 causes about $23 \%$ decrease in the relative seepage discharge.

5- About $12 \%$ increase in relative exit gradient and seepage discharge due to the increase in the pervious strata from 0.6 to 2.5 .

\section{REFERENCES}

[1] El-Fitiany, F.A., Seepage Under the Floors of Two Closely-Spaced Dams, Proceeding of Second Fluid Mechanics and Hydraulics Conference, AlMansoura University, Egypt, pp 515-531,1983.

[2] EL-Fitiany, F.A., Abdrabbo, F.M., Mahmoud, M.A., Seepage Under the Floor of 
A Pumping Station due to Cracks in the Canal Lining, Alexandria Engineering Journal, Vol. 32, No. 3, July 1993.

[3] El-Ganiny, M.A., Flow Underneath a Pair of Structures with Intermediate Filter on a Drained Stratum, Journal of Applied Mathematical Modeling, Vol. 10, No. 6, pp. 394-400, December, 1987.

[4] Harr, M.E., Groundwater and Seepage, McGraw-Hill Book Co., Inc., New York, N.Y., 1962.

[5] Hathoot, H.M., Seepage Beneath a Concrete Dam with a Downstream Filter, Journal of the Applied Mathematical Modeling, Vol. 10, No. 2, pp. 129-132, April, 1986.

[6] Nasr, R.I., Seepage Beneath Hydraulic Structures with Subsidiary Weirs, Ph. D. Thesis, Faculty of Engineering, Alexandria University, Alexandria, Egypt, 1987.

[7] Salem., M.N., Flow under Floors of Hydraulic Structures", Ph. D. Thesis, Faculty of Engineering, Zagazig University, Zagazig, Egypt, 1994.

[8] Salem, M.N., Elnikhily, E.H., Mowafy, M.H., Saad, M.B., Elsayed, A.H., (2004), Numerical and Experimental Study of Seepage under Hydraulic Structures with Cracked Floor and Sheet Piles, Al-Azhar Eighth International Conference, 24-27 Dec.

[9] Salem, M.N., Elnikhily, E.H., Mowafy, M.H., Saad, M.B., Elsayed, A.H., (2004), Application of Finite Element Model on Seepage Characteristics in New Esna Barrages, Al-Azhar Eighth International Conference, 24-27 Dec.

[10] Smith, I.M. and Griffiths, D.V., "Programming the Finite Element Method", Fourth Edition, John Wiley \& Son Ltd., 2004. 


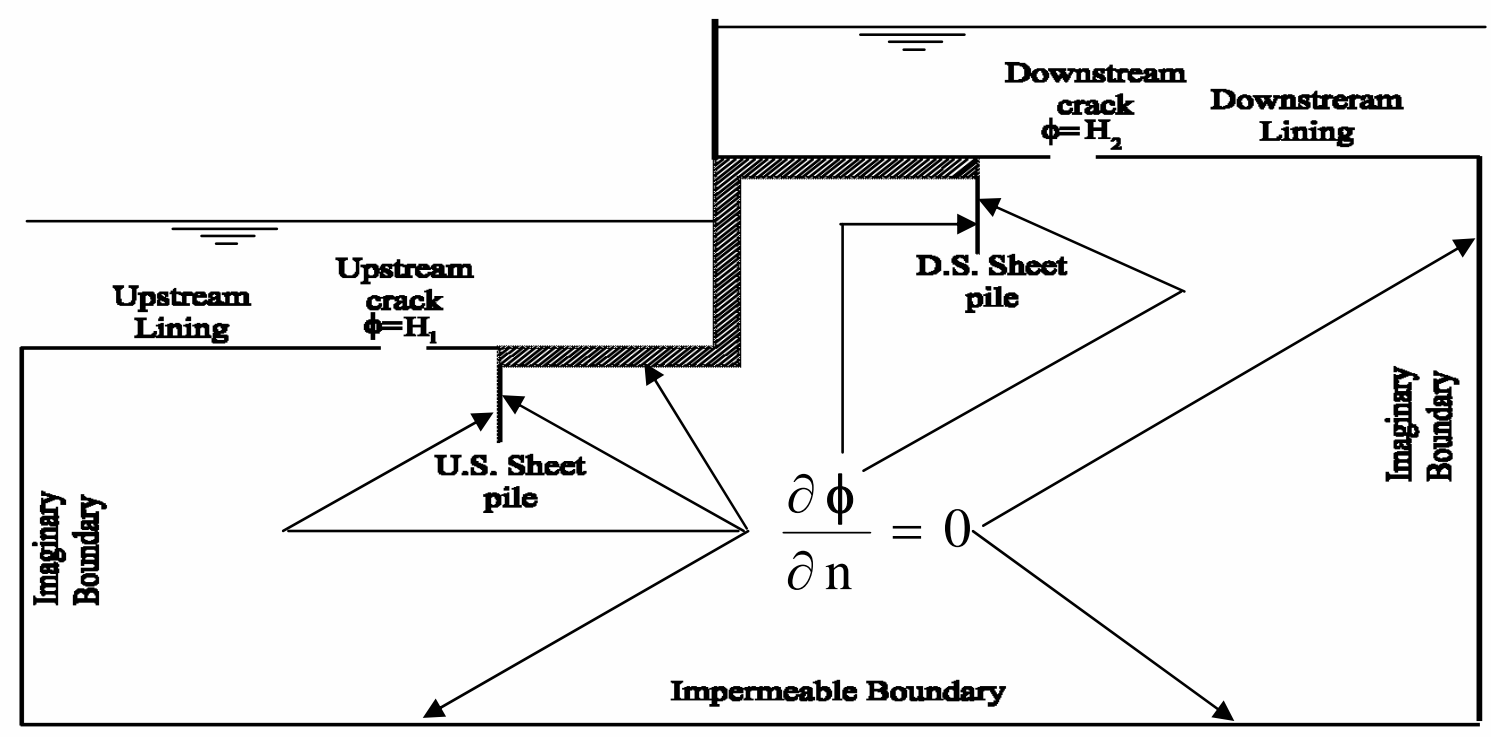

Fig. 1. Seepage domain and boundary conditions

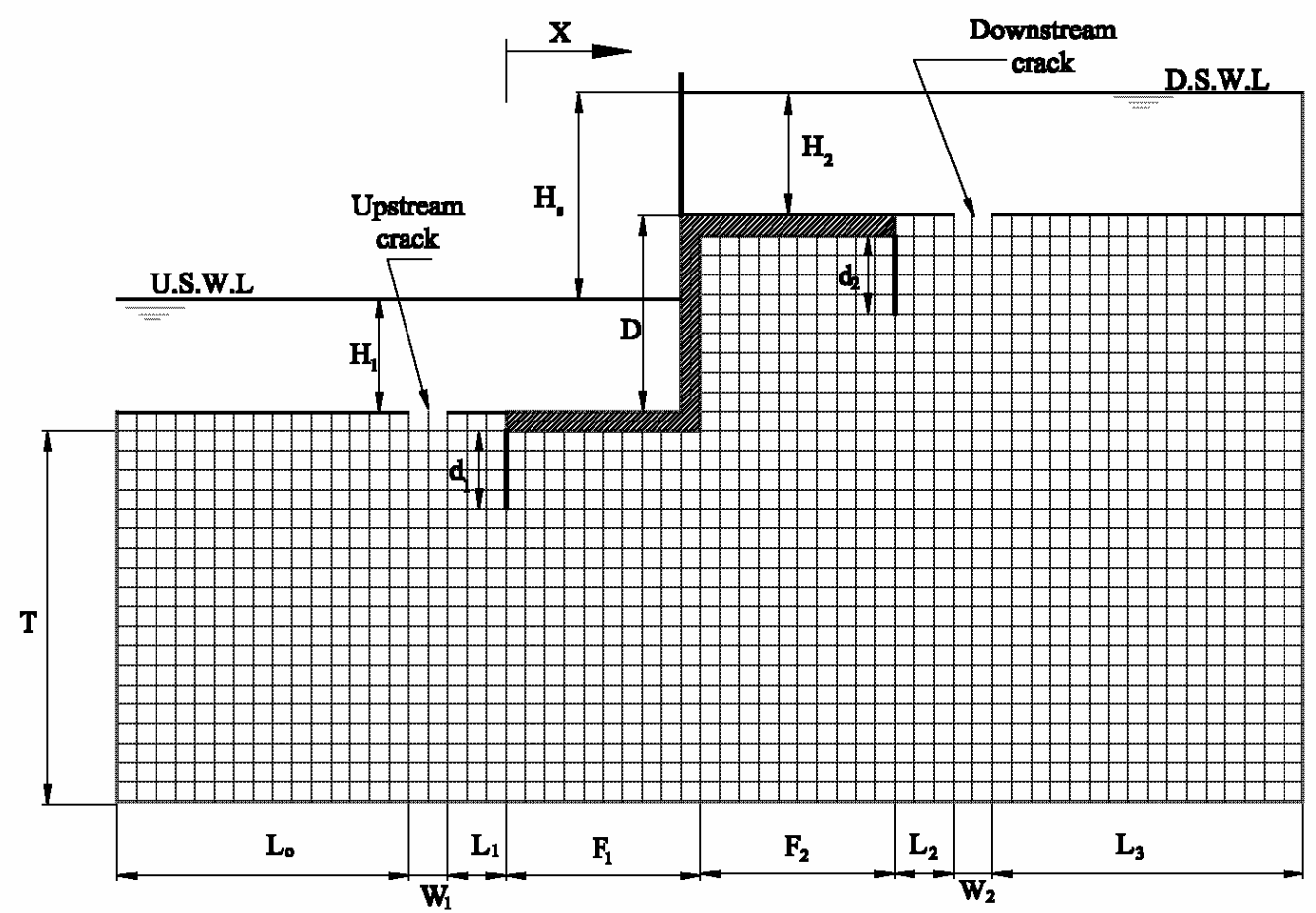

Fig. 2. Finite element mesh and the domain dimensions. 


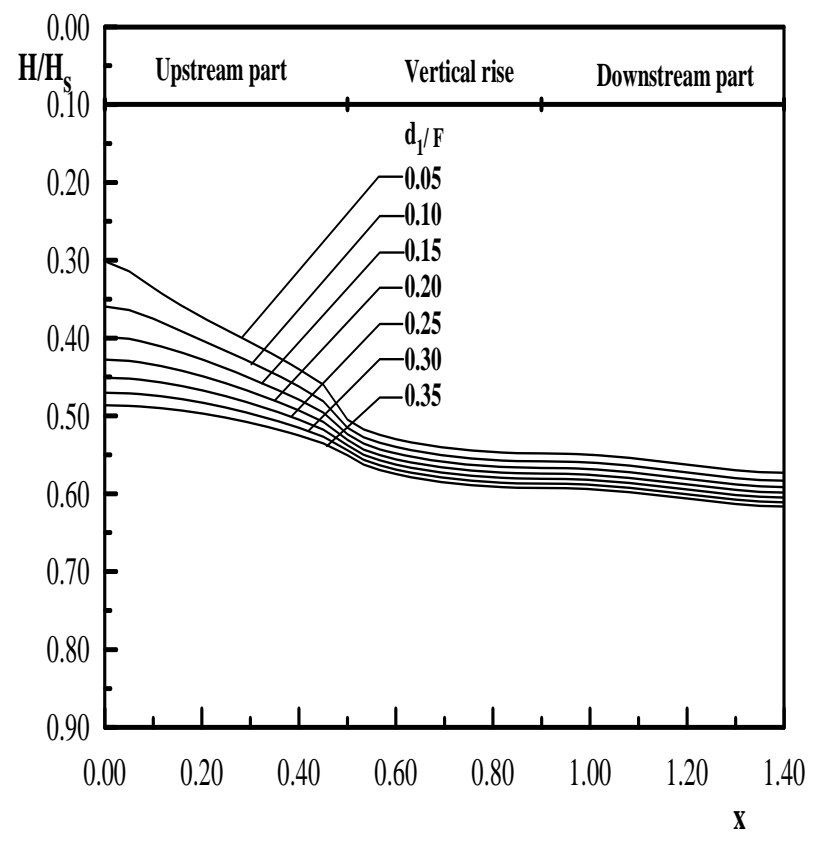

Fig. 3. Effect of the relative depth of the upstream sheet pile on the relative uplift pressure.

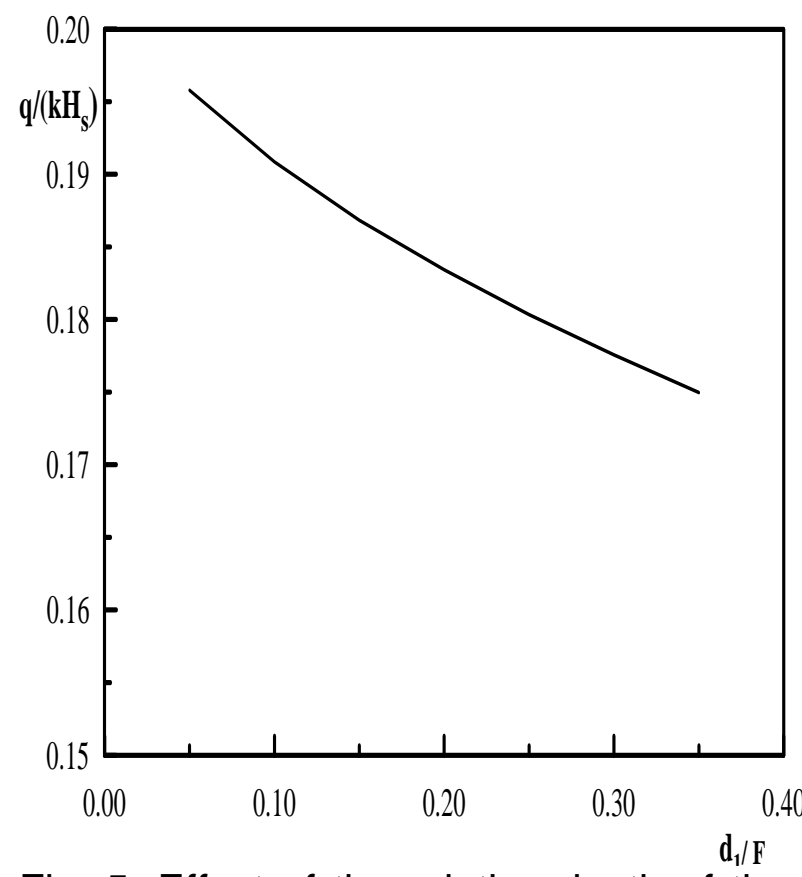

Fig. 5: Effect of the relative depth of the upstream sheet pile on the relative seepage discharge.

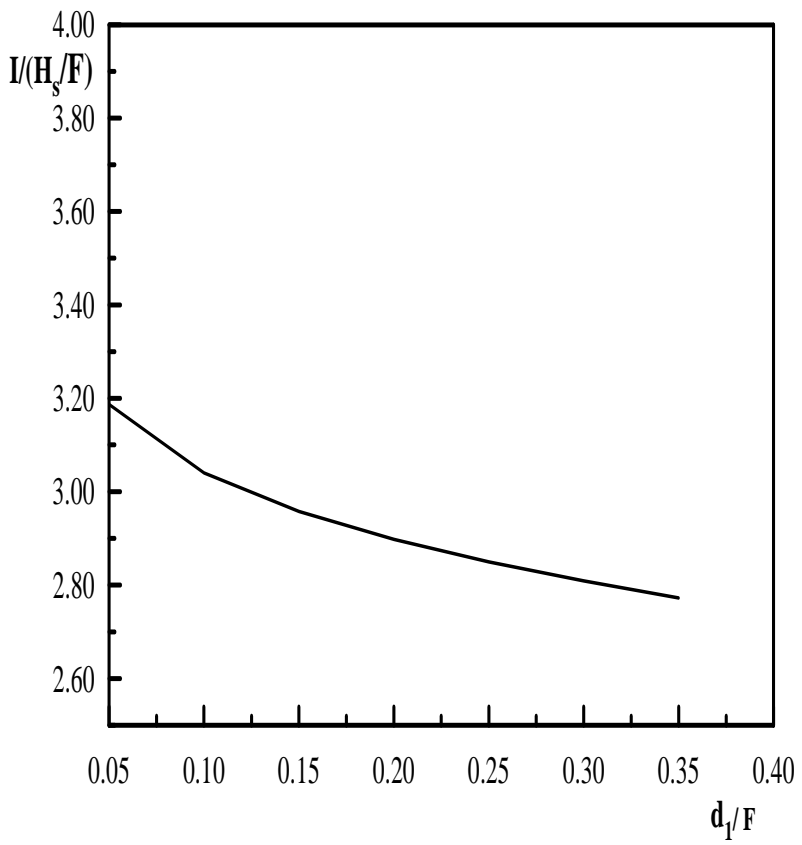

Fig. 4. Effect of the relative depth of the upstream sheet pile on the relative exit gradient.

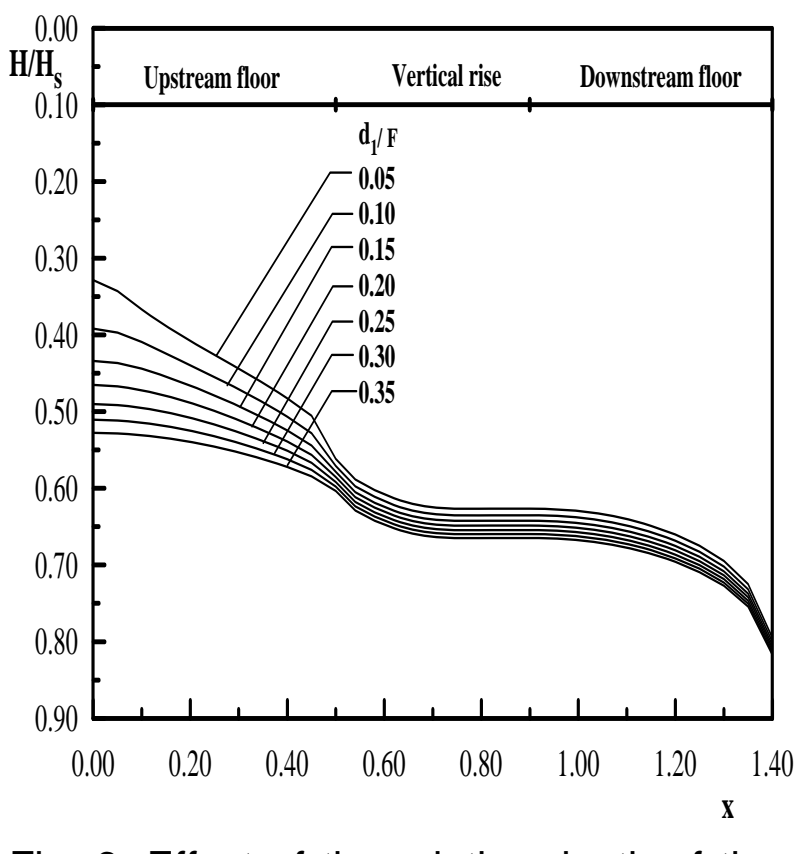

Fig. 6: Effect of the relative depth of the upstream sheet pile on the relative uplift pressure for no downstream sheet pile. 


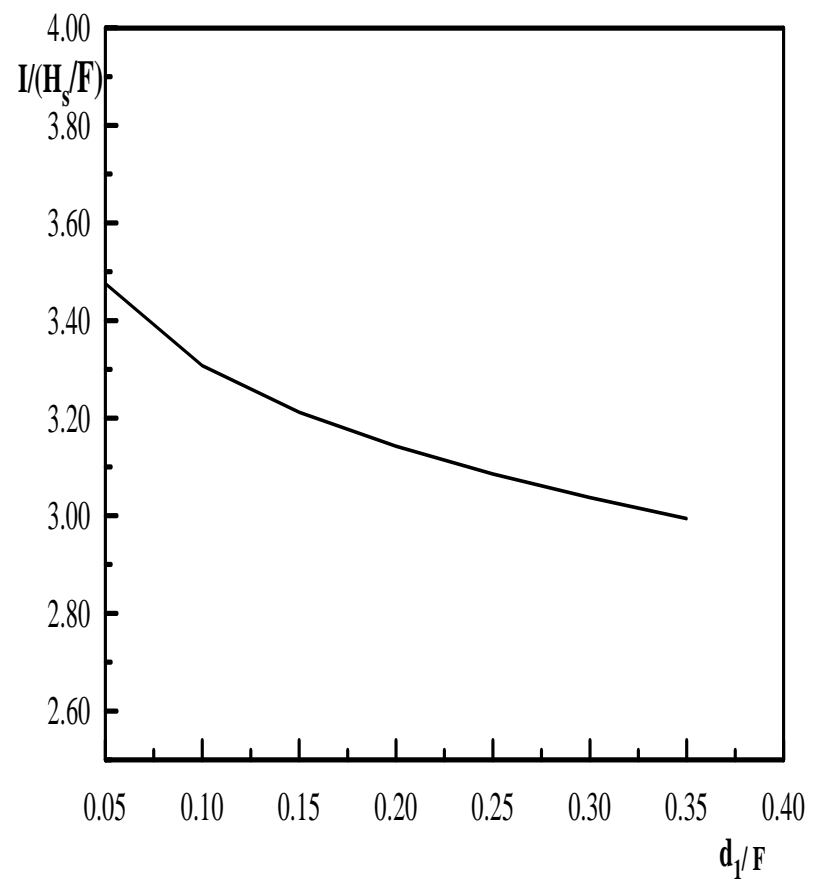

Fig. 7: Effect of the relative depth of the upstream sheet pile on the relative exit gradient for no downstream sheet pile.

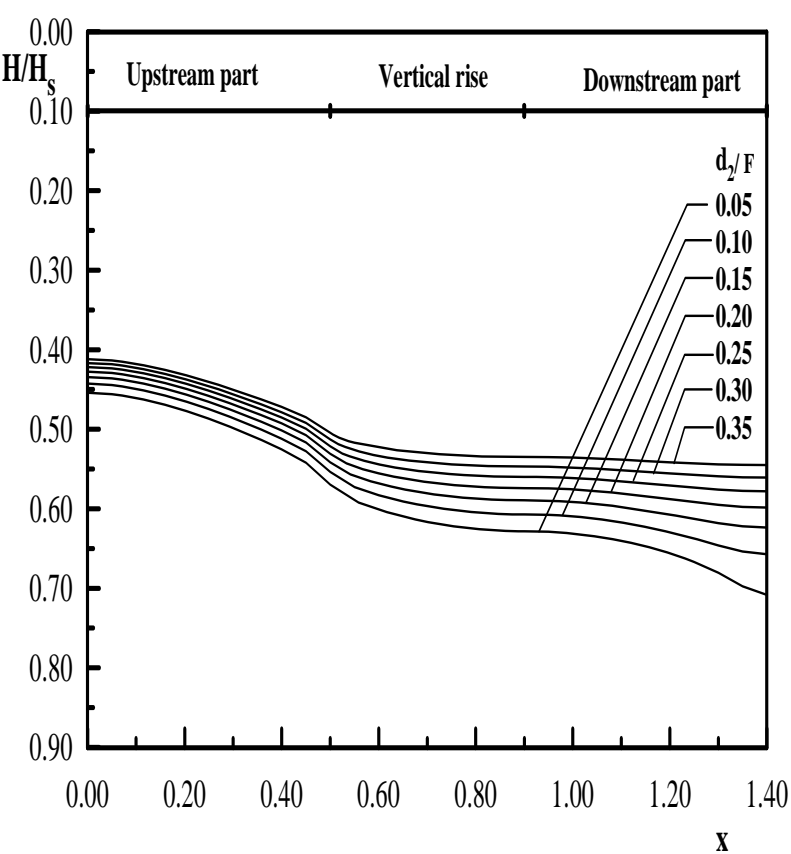

Fig. 9: Effect of the relative depth of the downstream sheet pile on the relative uplift pressure.

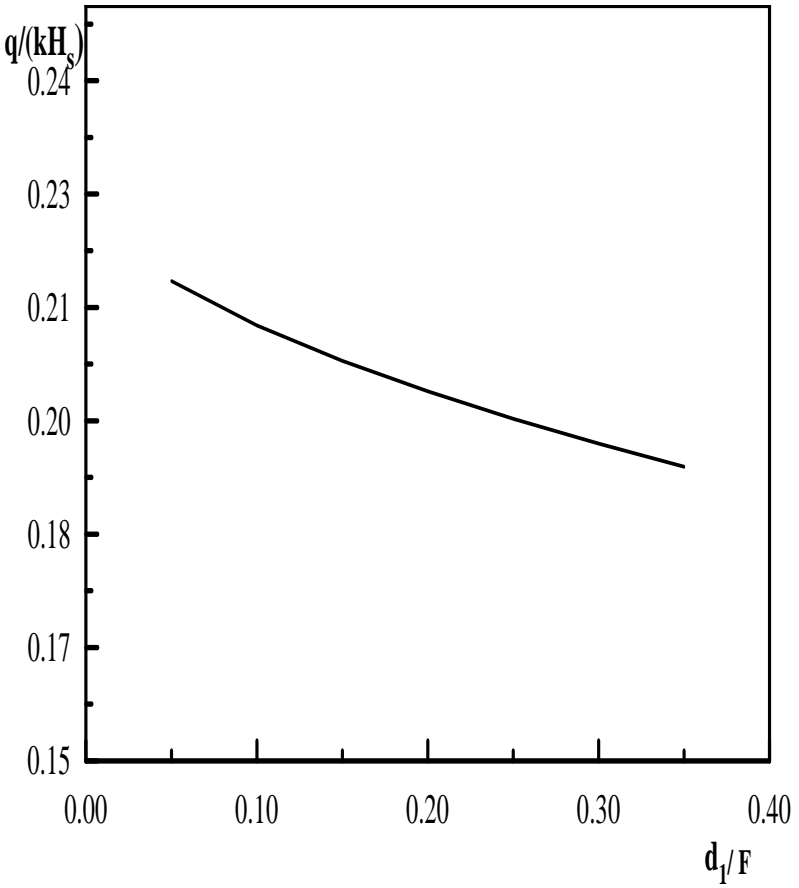

Fig. 8: Effect of the relative depth of the upstream sheet pile on the relative seepage discharge for no downstream sheet pile.

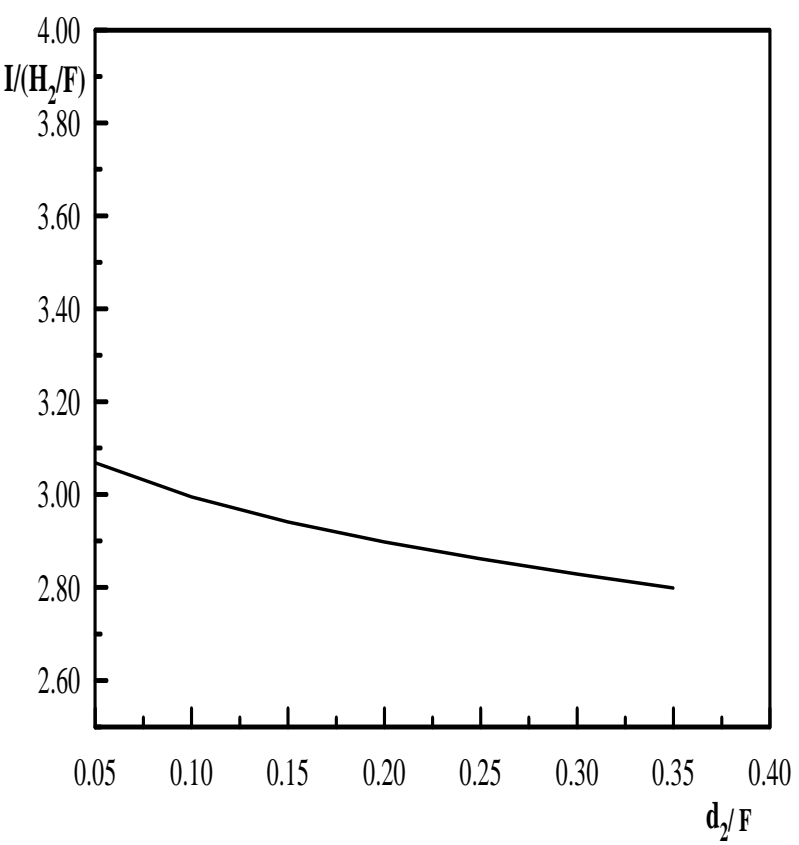

Fig. 10: Effect of the relative depth of the downstream sheet pile on the relative exit gradient. 


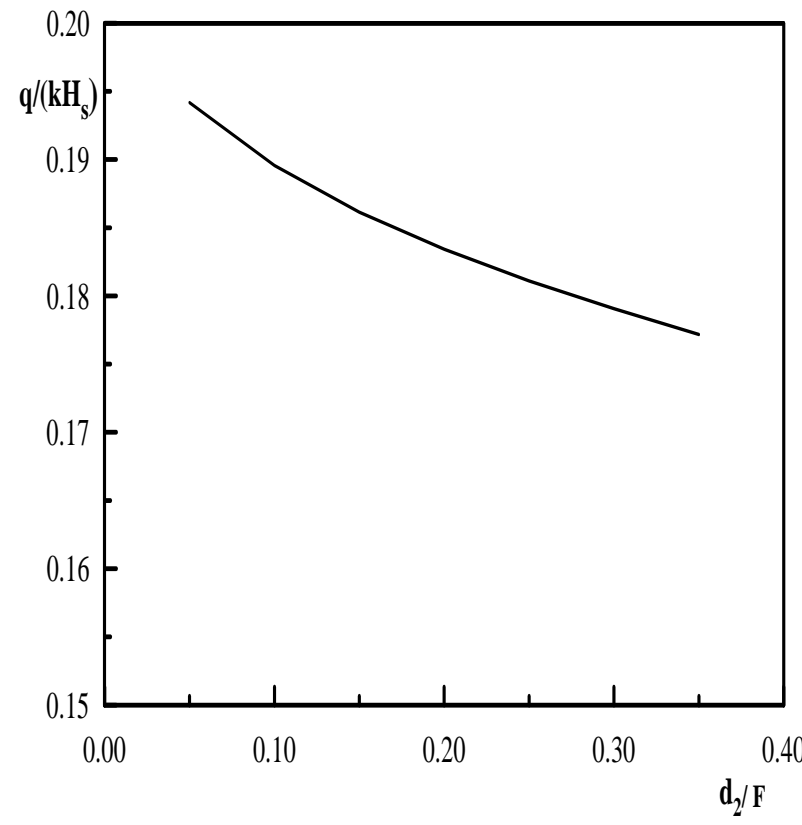

Fig. 11: Effect of the relative depth of the downstream sheet pile on the relative seepage discharge.

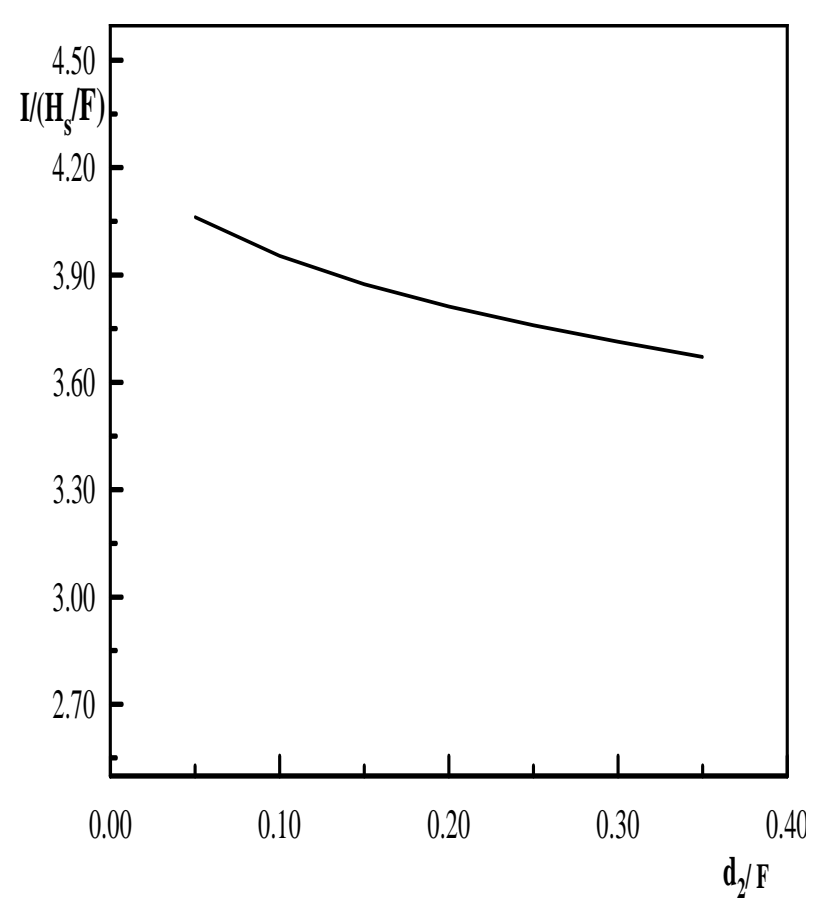

Fig. 13: Effect of the relative depth of the downstream sheet pile on the relative exit gradient.

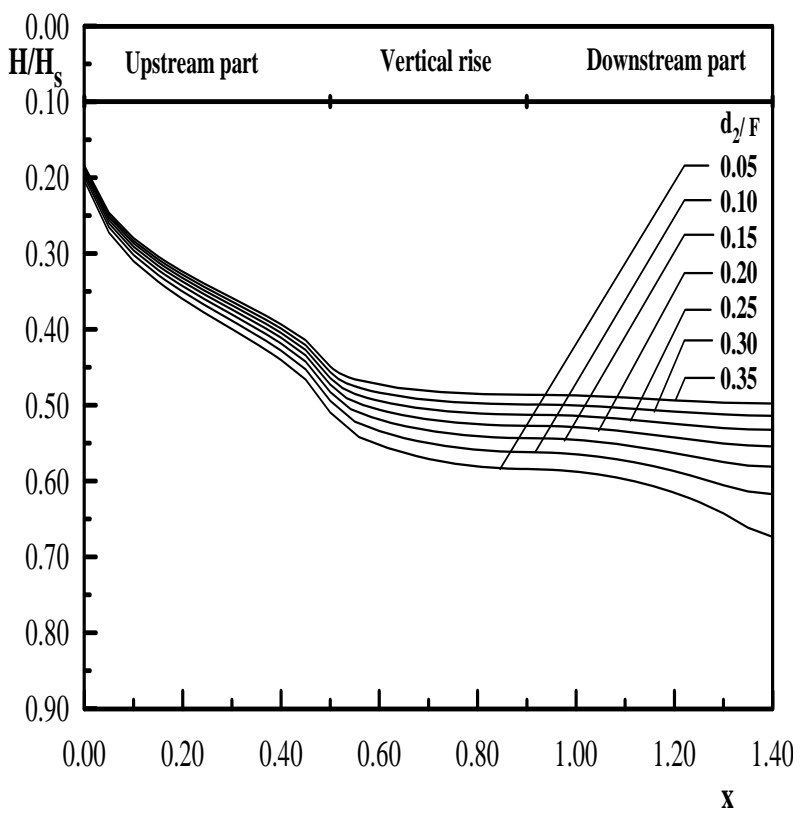

Fig. 12: Effect of the relative depth of the downstream sheet pile on the relative uplift pressure for no upstream sheet pile.

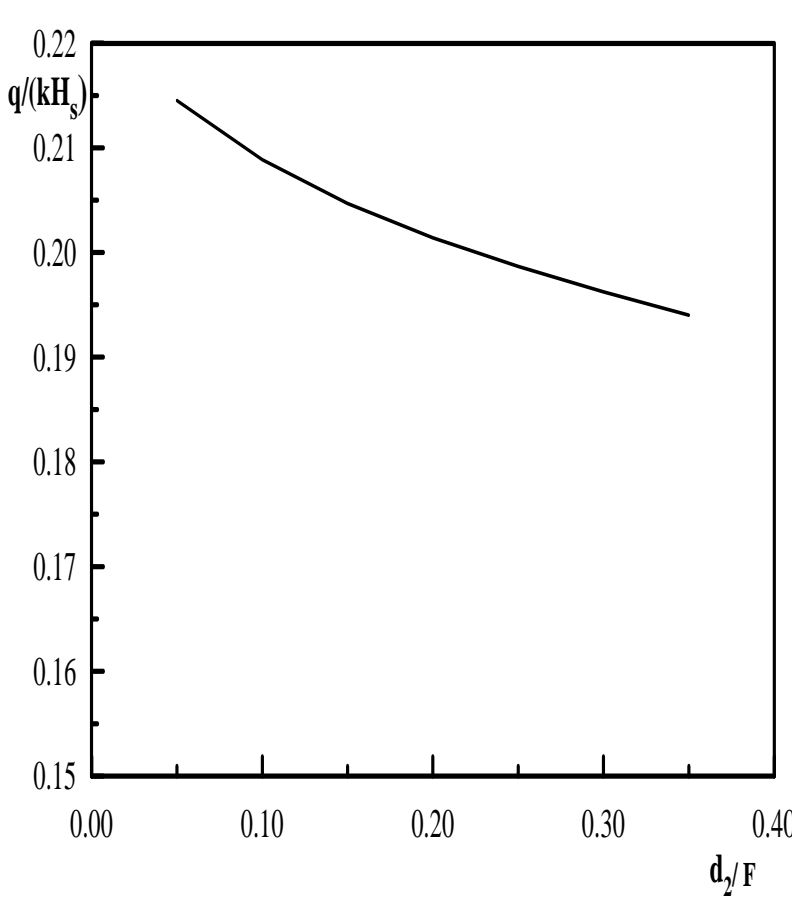

Fig. 14: Effect of the relative depth of the downstream sheet pile on the relative seepage discharge. 


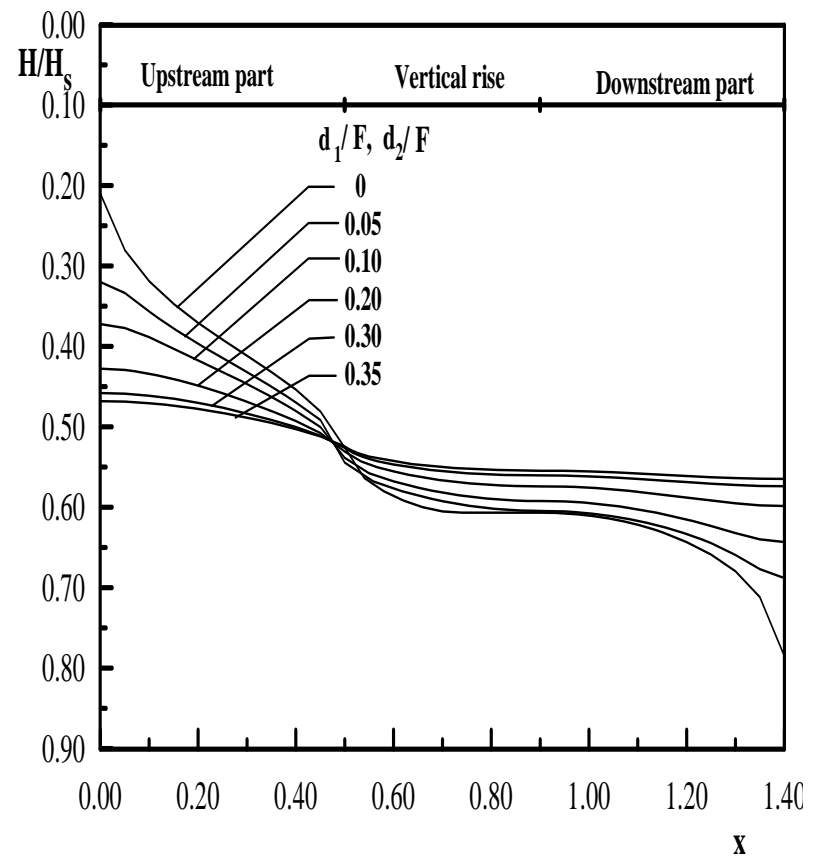

Fig. 15: Effect of the relative depth of the equal depth upstream and downstream sheet pile on the relative uplift pressure.

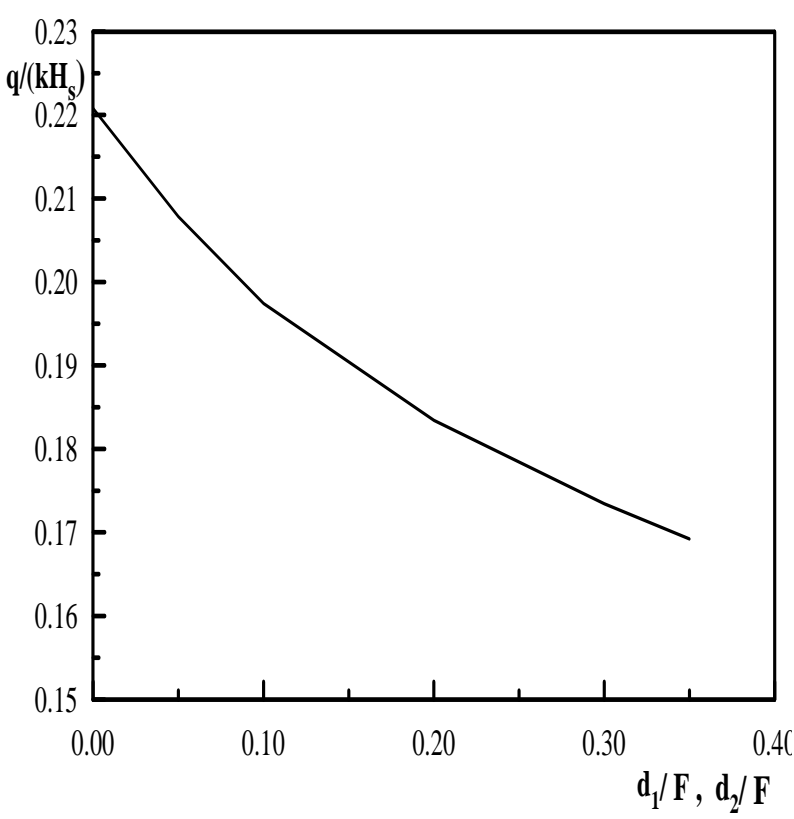

Fig. 17: Effect of the relative depth of the equal depth upstream and downstream sheet pile on the relative seepage discharge.

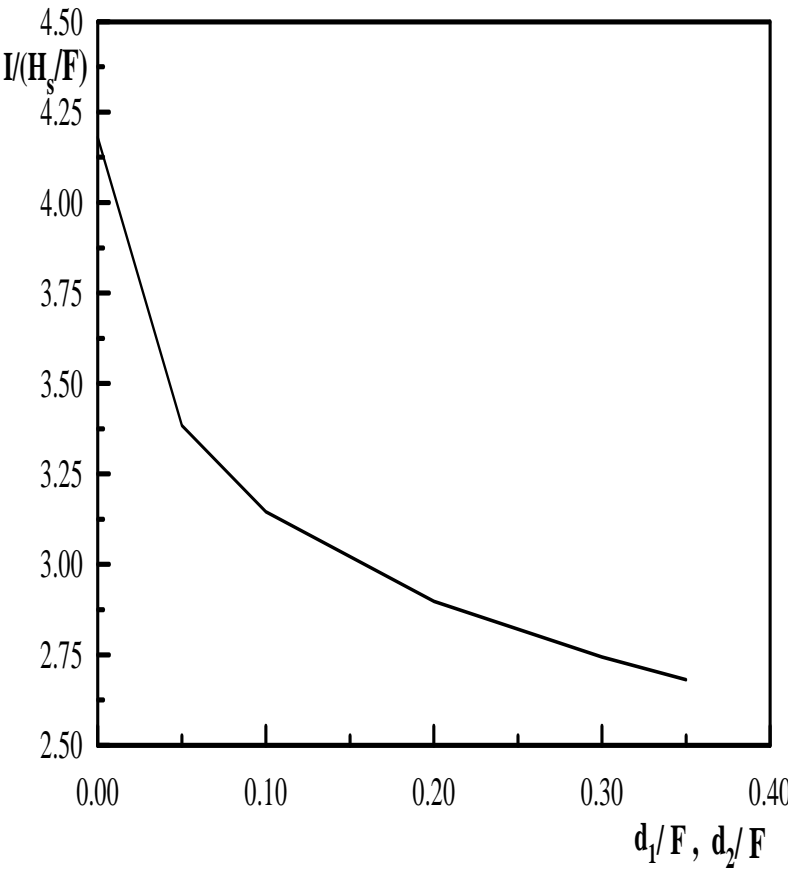

Fig. 16: Effect of the relative depth of the equal depth upstream and downstream sheet pile on the relative exit gradient.

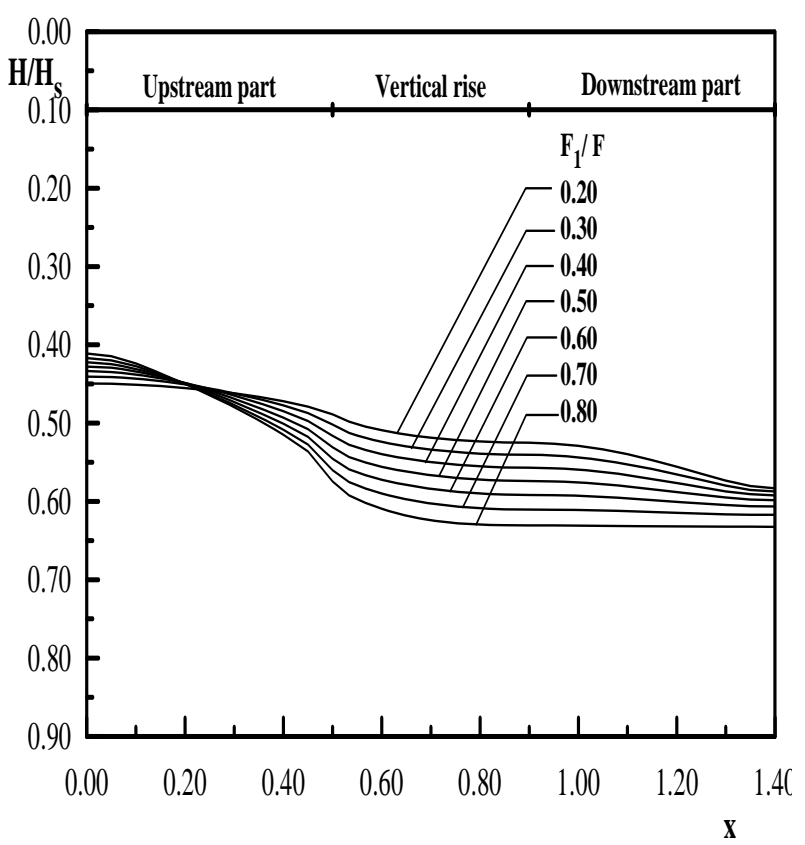

Fig. 18: Effect of the location of vertical rise on the relative uplift pressure. 


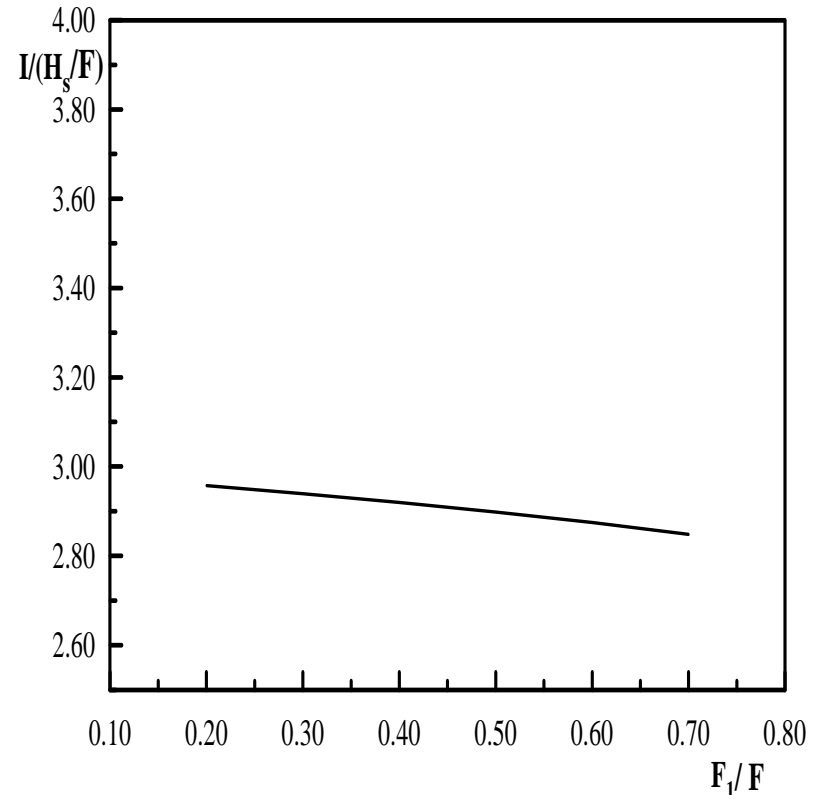

Fig. 19: Effect of the location of vertical rise on the relative exit gradient.

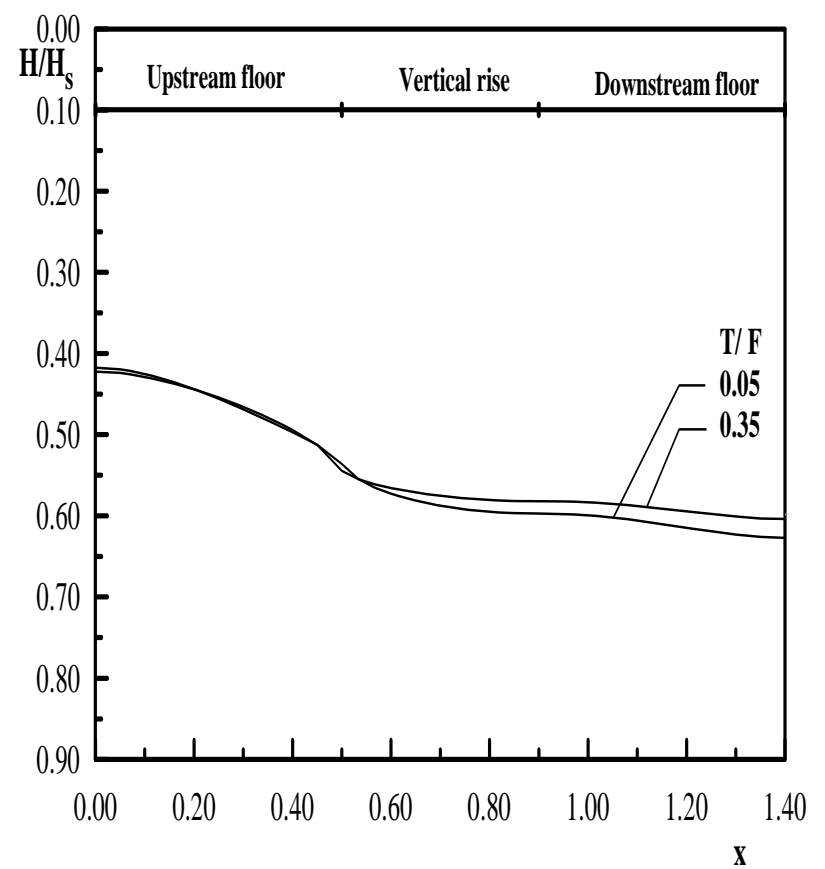

Fig. 21: Effect of the relative depth of the pervious strata on the relative uplift pressure.

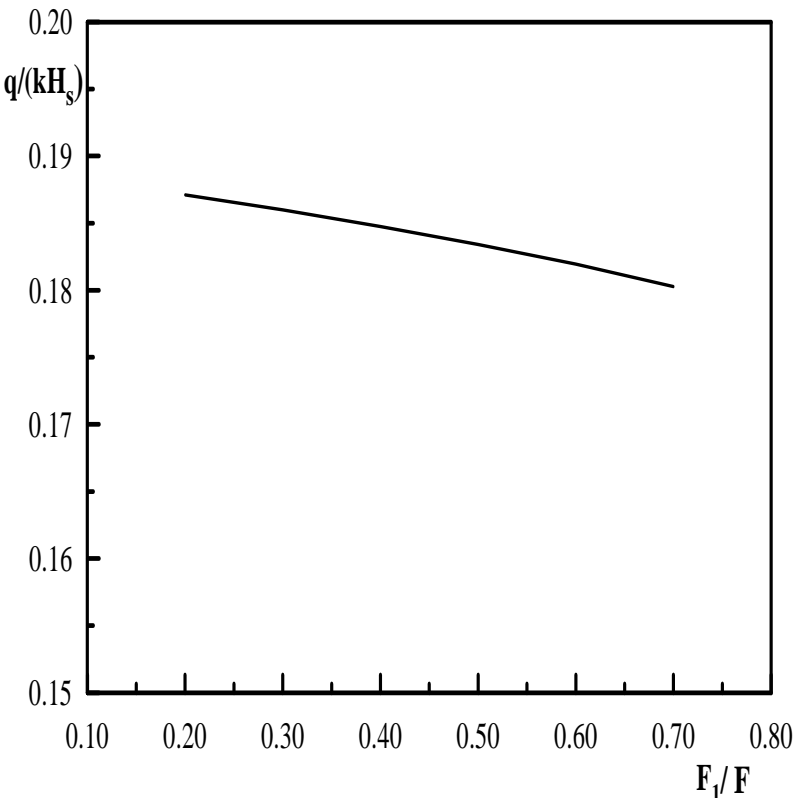

Fig. 20: Effect of the location of vertical rise on the relative seepage discharge.

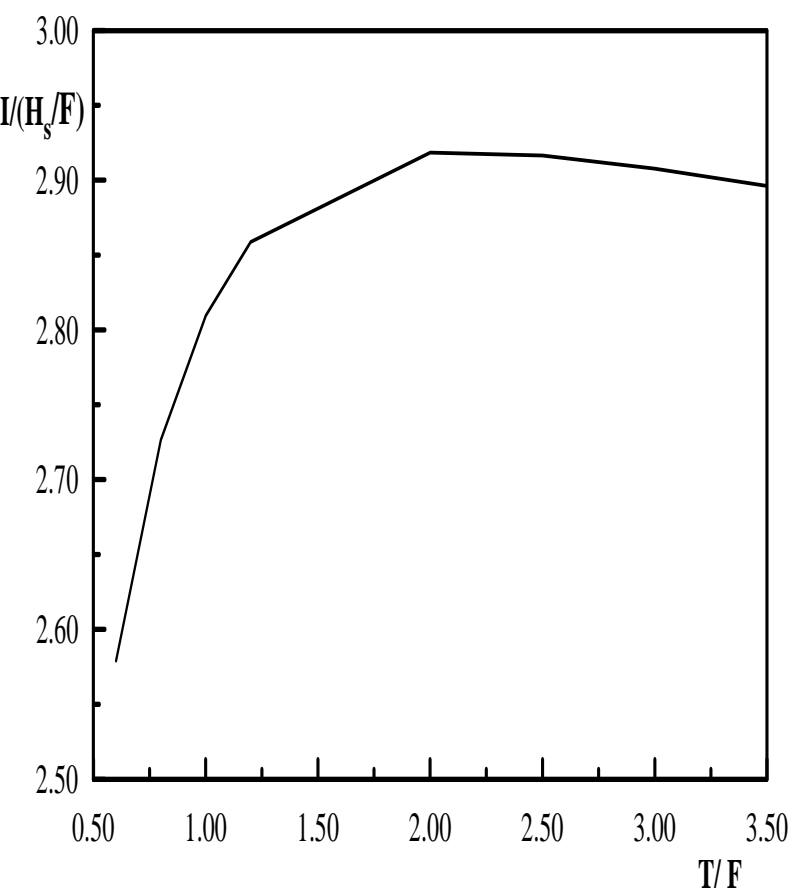

Fig. 22: Effect of the relative depth of the pervious strata on the relative exit gradient. 


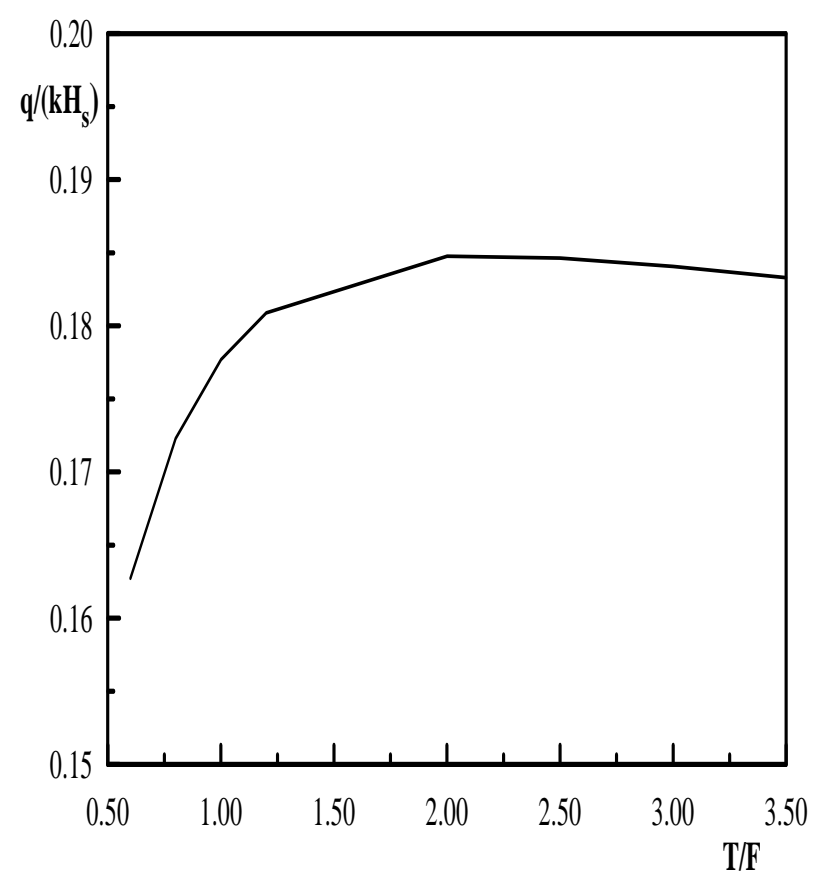

Fig. 23: Effect of the relative depth of the pervious strata on the relative seepage discharge. 